\title{
An unusual origin of the double left testicular artery in a male cadaver: a case report
}

Branislav Filipovic ${ }^{*}$, Lazar Stijak and Branka Filipovic ${ }^{2}$

\begin{abstract}
Introduction: Variations in the number and course of the testicular arteries, often coexisting with variations of the other branches arising from the abdominal aorta, are still reported to be of interest to urology surgeons.
\end{abstract}

Case presentation: During a routine dissection course, an unusual origin of the double left testicular artery was observed in the cadaver of a 68-year-old Caucasian man who donated his body to the Institute of Anatomy.

Conclusions: A deeper understanding of the variations of the testicular arteries is necessary for all physicians whose practice is related to the testicles and their vascular stalk.

\section{Introduction}

The testicular arteries are known to originate from the ventrolateral aspect of the abdominal aorta and descend obliquely to the pelvic cavity. Variations in the number and course of the testicular arteries, often coexisting with variations of the other branches arising from the abdominal aorta, are reported to be less frequent than the variations of the homologous veins [1,2]. The developmentally-based variation of origin dealt mostly with the debranching from the renal artery, either main or accessory [3-7]. Although other anatomical peculiarities were related to the same cadaver, such as an early division of the right axillary artery, the presence of the axillary arch on the right side, and the evidence of the accessory renal artery of the same side of the double testicular artery, our aim was to describe, according to the literature, the rarest of the evidenced anatomical variations.

\section{Case presentation}

During routine dissection classes, two left testicular arteries were revealed in the cadaver of a 68 -year-old Caucasian man who donated his body through the body donation program: one was medial, originating from an accessory renal artery; the other was lateral, debranching from the common trunk together with the left inferior

\footnotetext{
*Correspondence: filipovic.branislav@gmai.com

"Institute of Anatomy "Niko Miljanic", University of Belgrade, Faculty of Medicine, 4/2 Dr Subotica, 11000, Belgrade, Serbia

Full list of author information is available at the end of the article
}

suprarenal artery. The medial artery was smaller in caliber $(0.9 \mathrm{~mm})$ and followed the course of the regular testicular vein. The lateral left testicular artery was slightly larger $(1.2 \mathrm{~mm})$ and pierced the tissue of the suprarenal gland immediately after debranching. The lateral artery ran in front of the left renal vein, arched laterally afterwards, ventrally crossed the inferior pole of the left kidney, and followed the lateral border of the psoas major muscle. After a short pathway on the anterior surface of the psoas major, taking the medial course, it joined the medial artery at the entrance of the funiculus spermaticus. The lateral artery was accompanied by two veins, tributaries of the left suprarenal vein. The right testicular artery had the origin and pathway described in most anatomy textbooks (Figure 1). In the man's medical chart, no sign of any kind of urological disorder was noted, and no fertility problem was noted in his personal medical record. It was not the only anatomical variation found: a division of the axillary artery to the superficial and deep brachial artery was present in the right axilla, and on the left side an axillary arch was revealed.

\section{Discussion}

We present a case of double left testicular artery in which one branch originated from the left renal accessory artery and the other branch arose from the common trunk with the left inferior suprarenal artery. The special feature of this case is that the testicular artery on the left side is double, and none of the two 

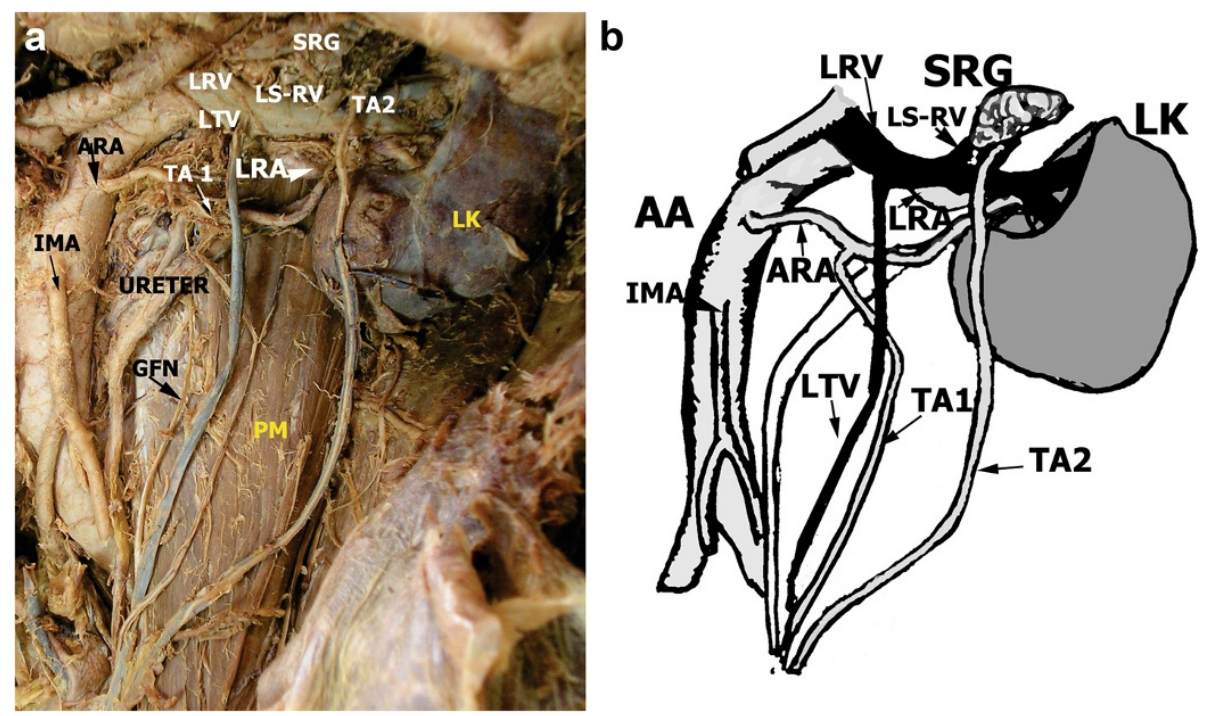

Figure 1 The photo and schematic approach of the case. TA1 and TA2. Medial and lateral testicular arteries. ARA - accessory renal artery. LRA - left renal artery. SRG - part of the suprarenal gland pierced by the lateral testicular artery (TA2). LK - left kidney. AA - abdominal aorta. IMA - inferior mesenteric artery. LS-RV - left suprarenal vein. GFN - genitofemoral nerve. PM - psoas major muscle.

arterial vessels arose from the abdominal aorta. Yet cases concerning the origin of the double left testicular artery from the common trunk with the superior adrenal and the inferior mesenteric artery have been presented [8]. The prevalence of variations upon gonadal arteries was reported to be 16 out of 180 specimens obtained from human fetuses and to be more frequent in men than in women [9]. The variations of the testicular artery could be divided in two groups: (a) variations in the branching level, regarding the vertebral column, or arising locus of the renal arteries (above or below the branching level of the renal arteries) [6] and (b) variation in number, origin, and course; this variation appeared to be more frequent on the right side $[9,10]$. Also, common origin with the inferior suprarenal artery has been reported $[1,8]$. Testicular arteries were documented to rise from lumbar, renal, accessory renal, middle, and, occasionally, superior suprarenal arteries $[4,7,11]$. In a recent case presentation, Paraskevas et al. [12] (2011) described a high origin (above the expected level of branching) of the left testicular artery in a common trunk with the inferior phrenic artery. The bilateral branching of the ovarian arteries from the accessory renal arteries has also been revealed [13]. Most of the variations, including those described in this paper, have their roots in the embryology of the testes and the contemporaneous blood supply of each phase of development: mesonephros itself was described to have irrigation from nine mesonephric arteries: superior or cranial, middle, and inferior or caudal (three in each group). The caudal group gives rise to the testicular arteries, whereas the middle forms renal arterial vessels [3]. In our case, both vessels on the left side seemed to originate from the middle group. Double testicular arteries have been obtained in two out of 32 overlooked specimens of human fetuses [14], and both of the testes had an abdominal localization. Whether the arteries supplying undescended testes have variations in number and origin remains unclear, although a different anastomotic network is present in the undescended testicles [15]. A deeper understanding of these variations and their special relationships to adjacent vessels is especially significant in avoiding sometimes serious complications in clinical operation and other procedures, such as the Fowler-Stephens technique [16], and in recognizing the causes of genital disorders, such as cryptorchidism, and their adequate treatment in order to preserve the functionality of the undescended testis.

\section{Conclusions}

Although many kinds of variations of the origin, direction, and pattern of the testicular arteries have been described, this is a rare case of double testicular artery on the left side. Neither of the two branches originated from the abdominal aorta but from the left inferior suprarenal artery and from the left renal artery. The awareness of such variation is important for all surgeons whose interest is related to the testicular blood vessels or, generally, blood vessels of the retroperitoneum.

\section{Consent}

Written informed consent was obtained from the patient's next of kin for publication of this manuscript 
and accompanying images. A copy of the written consent is available for review by the Editor-in-Chief of this journal.

\section{Competing interests}

The authors declare that they have no competing interests.

\section{Authors' contributions}

In the order listed on the title page, BF prepared the manuscript for publication. $L S$, along with his students, performed anatomical dissection. BF edited the manuscript and prepared the final version for submission. All authors read and approved the final manuscript.

\section{Acknowledgments}

We dedicate this article to the memory of our late professor and teacher, Sava Perovic, member of the Serbian Academy of Science and Arts.

\section{Author details}

'Institute of Anatomy "Niko Miljanic", University of Belgrade, Faculty of Medicine, 4/2 Dr Subotica, 11000, Belgrade, Serbia. ${ }^{2}$ Department of Gastroenterohepatology, Clinical and Hospital Center "Bezanijska Kosa", Autoput s/n, 11080, Belgrade, Serbia.

Received: 3 May 2012 Accepted: 21 June 2012

Published: 31 August 2012

\section{References}

1. Asala S, Chaudhary SC, Masumbuko-Kahamba N, Bidmos M: Anatomical variations in the human testicular blood vessels. Ann Anat 2001, 183:545.

2. Deepthinath R, Satheesha Nayak B, Mehta RB, Bhat S, Rodrigues V, Samuel VP, Venkataramana V, Prasad AM: Multiple variations in the paired arteries of the abdominal aorta. Clin Anat 2006, 19:566-568.

3. Xue HG, Yang CY, Ishida S, Ishizaka K, Ishihara A, Ishida A, Tanuma K: Duplicate testicular veins accompanied by anomalies of the testicular arteries. Ann Anat 2005, 187:393-398.

4. Bordei P, Sapte E, lliescu D: Double renal arteries originating from the aorta. Surg Radiol Anat 2004, 26:474-479.

5. Loukas M, Aparicio S, Beck A, Calderon R, Kennedy M: Rare case of right accessory renal artery originating as a common trunk with the inferior mesenteric artery: a case report. Clin Anat 2005, 18:530-535.

6. Singh G, Ng YK, Bay BH: Bilateral accessory renal arteries associated with some anomalies of the ovarian arteries: a case study. Clin Anat 1998, 11:417-420.

7. Yalçin B, Komesli GH, Ozkok Y, Ozan H: Vascular anatomy of the normal and undescended testes: surgical assessment of the anastomotic channels between testicular and deferential arteries. Urology 2005, 66:854-857.

8. Jyothsna P, Mohandas Rao G, Somayaji SN, Ashwini LS: Multiple vascular anomalies including testicular, suprarenal arteries and lumbar vein. North Am J Med Sci 2012, 4:154-156.

9. Felix W: \. In Manual of Human Embryology, Volume 2. Edited by Keibel F, Mall FP. Philadelphia, London: Lippincott; 1912:820-825.

10. Siniluoto TM, Hellstrom PA, Paivansalo MJ, Leinonen AS: Testicular infarction following ethanol embolization of a renal neoplasm. Cardiovasc Intervent Radiol 1988, 11:162-164.

11. Sampaio FJ, Favorito LA, Freitas MA, Damiao R, Gouveia E: Arterial supply of the human fetal testis during migration. J Urol 1998, 161:1603-1605.

12. Sylvia S, Kakarlapudi SV, Vollala VR, Potu BK, Jetti R, Bolla SR, Rao M, Pamidi N: Bilateral variant testicular arteries with double renal arteries. Cases J 2009, 2:114.

13. Paraskevas GK, loannidis O, Raikos A, Papaziogas B, Natsis K, Spyridakis I, Kitsoulis P: High origin of a testicular artery: a case report and review of the literature. J Med Case Reports 2011, 5:75.

14. Ciçekcibaşi AE, Salbacak A, Seker M, Ziylan T, Büyükmumcu M, Uysal II: The origin of gonadal arteries in human fetuses: anatomical variations. Ann Anat 2002, 184:275-279.

15. Petru B, Elena S, Dan I, Constantin D: The morphology and the surgical importance of the gonadal arteries originating from the renal artery. Surg Radiol Anat 2007, 29:367-371.
16. Acar HI, Yazar F, Ozan H: Unusual origin and course of the testicular arteries. Surg Radiol Anat 2007, 29:601-603.

\section{doi:10.1186/1752-1947-6-267}

Cite this article as: Filipovic et al: An unusual origin of the double left testicular artery in a male cadaver: a case report. Journal of Medical Case Reports 2012 6:267.

\section{Submit your next manuscript to BioMed Central and take full advantage of:}

- Convenient online submission

- Thorough peer review

- No space constraints or color figure charges

- Immediate publication on acceptance

- Inclusion in PubMed, CAS, Scopus and Google Scholar

- Research which is freely available for redistribution 